\title{
Personal viewpoint
}

\section{The quiet pleasure of browsing through vital statistics}

Publication of an 800 page compendium ${ }^{1}$ of vital statistics on gastrointestinal disease frequency in the United States, with its profusion of figures detailing the frequency of common complaints, rarer conditions, cancer, and hepatobiliary disease allows speculation a free rein on why and how.

Browsing through the pages raises some intriguing questions. Digestive complaints accounted for five to 10 per cent of office visits in 1989-90, irrespective of age or sex. However, digestive complaints were about 15 per cent more common in male children aged four and under, while male children were 50 per cent more likely to be prescribed medications. How did these differences arise? It is not immediately obvious that male children require more treatment, though they might be perceived to do so for general cultural reasons. The rates of office based contracts for gastroenteritis in children aged two and under did not differ materially and it seems unlikely that male children were more prone to serious disease.

At all later ages digestive complaints were more common, 20 to 40 per cent, in women than in men, and treatments were prescribed about 50 per cent more commonly for them. Differences in overall patterns seem more likely to be accounted for by variations in the impact of symptoms due to ill-attributed disease than to specific illnesses. These ill-defined symptoms would generally fall within the upper and lower digestive system sets.

Table I shows the frequency of upper digestive complaints in male and female subjects for gastritis or duodenitis, frequent indigestion, symptomatic ulcer, and hospital discharges with ulcer disease. Complaints of gastritis or duodenitis (self diagnosed) or frequent indigestion were both marginally more common in women than men at all ages (Table I). Self reported ulcer, however, was more common in men than women, and at least as common as self reported indigestion. Linking the two patterns together is unfair because data were obtained at different times in different ways, but the ratio of ulcer to frequent indigestion was comparatively high in men, and low in women. Whether this reflects true differences or variations in response to symptoms is unclear.

By contrast, complaints of constipation, spastic colon or mucous colitis and irritable bowel were consistently about twice as common, or more in women as in men (Table II).

TABLE I Upper abdominal complaints per 1000 population in the United States

\begin{tabular}{|c|c|c|c|c|c|c|c|c|}
\hline \multirow[b]{2}{*}{ Age } & \multicolumn{2}{|c|}{$\begin{array}{l}\text { Gastritis/ } \\
\text { duodenitis }\end{array}$} & \multicolumn{2}{|c|}{$\begin{array}{l}\text { Frequent } \\
\text { indigestion } \dagger\end{array}$} & \multicolumn{2}{|c|}{$\begin{array}{l}\text { Presently } \\
\text { active ulcer }\end{array}$} & \multicolumn{2}{|c|}{$\begin{array}{l}\text { Ulcer } \\
\text { discharges } \$\end{array}$} \\
\hline & Male & Female & Male & Female & Male & Female & Male & Female \\
\hline $\begin{array}{l}17-44 \\
25-44 \\
45-64 \\
65+\end{array}$ & $\begin{array}{r}7 \\
13 \\
11\end{array}$ & $\begin{array}{r}8 \\
15 \\
18\end{array}$ & $\begin{array}{r}18 \\
-\overline{3} \\
40\end{array}$ & $\begin{array}{r}18 \\
37 \\
41\end{array}$ & $\begin{array}{l}- \\
34 \cdot 0 \\
54 \cdot 4 \\
58 \cdot 4\end{array}$ & $\begin{array}{l}\overline{25 \cdot 0} \\
39 \cdot 0 \\
33 \cdot 4\end{array}$ & $\begin{array}{l}\overline{1} \cdot 2 \\
3 \cdot 6 \\
9 \cdot 7\end{array}$ & $\begin{array}{l}- \\
0 \cdot 9 \\
2 \cdot 6 \\
8 \cdot 1\end{array}$ \\
\hline
\end{tabular}

*Self reported gastritis or duodenitis 1979-81. National Centre for Health Statistics.

†Self reported frequent indigestion 1988. National Centre for Health Statistics.

†Self reported peptic ulcer 1976-80. Second National Health and Nutrition Examination Survey.

SAverage annual discharge rate peptic ulcer 1983-87. Commission

Professional and Hospital Activities.
Death rates from diverticulosis were also considerably greater in women than in men, although hospital discharge rates were only slightly less in men than in women.

The impression gained, which matches clinical experience, is that the greater overall frequency of digestive complaints in women reflects an excess of functional disorders. The basis is unclear. Misdiagnosis of gynaecological problems is possible, though it seems unlikely on such a massive scale. In addition, the greater death rate in women from diverticular disease argues for a real difference in frequency of bowel complaints from men.

As found by examining educational attainment, occupational mortality or morbidity ${ }^{4-6}$ a strong inverse association was detectable between social class (here as income) and peptic ulcer occurrence. Similar trends were also observed with inverse associations between income and the self reported prevalence of constipation and the occurrence of haemorrhoids, the trend being much stronger for constipation than for haemorrhoid occurrence. Whether the trends for constipation and haemorrhoids reflect real differences or perceptive variations is unclear.

Examination of time trend data confirms a steep decline in the need for admission for duodenal ulcer. However, in contradistinction to the United Kingdom the decline seems to be at all ages, albeit with an upward trend for duodenal ulcer bleeding in women. ${ }^{7}$

A moderate decline in admission rates for appendicitis reflects United Kingdom experience, ${ }^{8}$ and there was also a very steep decline in mortality associated with it. By contrast there is evidence, as elsewhere, of an increase in the occurrence of acute pancreatitis similar to the United Kingdom, ${ }^{9}$ and also of chronic pancreatitis. The reasons for the increases are unclear. Rising alcohol consumption may be partially responsible - but is unlikely to account for an increase in the disease in older people. Gall stones are a likely factor, but maybe not alone. Data for digestive cancer confirm an overall decline for gastric cancer (but within it, as in the United Kingdom, a rise in the frequency of cancer of the cardia). These data are matched by evidence of an increased frequency of oesophaged adenocarcinoma noted before in the United Kingdom and the United States of America. ${ }^{1011}$ It is tempting to link these

TABLE II Lower abdominal complaints per 1000 population in the United States

\begin{tabular}{|c|c|c|c|c|c|c|c|c|}
\hline \multirow[b]{2}{*}{ Age } & \multicolumn{2}{|c|}{ Constipation $^{\star}$} & \multicolumn{2}{|c|}{ Spastic colon† } & \multicolumn{2}{|c|}{ Irritable bowel } & \multicolumn{2}{|c|}{$\begin{array}{l}\text { Diverticulosis } \\
\text { discharges } \$\end{array}$} \\
\hline & Male & Female & Male & Female & Male & Female & Male & Female \\
\hline Under 45 & $5 \cdot 7$ & $15 \cdot 5$ & - & - & - & - & - & - \\
\hline $25-44$ & - & - & 13 & 51 & $5 \cdot 2$ & $16 \cdot 1$ & - & - \\
\hline $15-44$ & -7 & - & - & $\overline{1}$ & - & $\overline{12}$ & 0.03 & 0.0 \\
\hline 45-64 & $8 \cdot 7$ & $32 \cdot 3$ & 22 & 61 & $4 \cdot 4$ & $13 \cdot 3$ & $0 \cdot 24$ & $0 \cdot 31$ \\
\hline $65-74$ & $21 \cdot 2$ & $67 \cdot 3$ & 25 & 51 & $\overline{0}$ & $\bar{x}$ & - & - \\
\hline $65+$ & - & - & - & - & $10 \cdot 9$ & $16 \cdot 5$ & 0.91 & 1.00 \\
\hline $75+$ & $68 \cdot 6$ & $115 \cdot 4$ & - & - & - & - & - & - \\
\hline
\end{tabular}

*Self reported constipation 1983-87. National Health Interview Survey. ${ }^{3}$ †Self reported spastic colon or mucous colitis 1976-80. Second National Health and Nutrition Examination Survey.

fFirst listed diagnoses of irritable bowel at office visits 1980-81. National Ambulatory Care Medical Survey.

SHospital discharges, diverticulosis, non-Federal short stay hospital 1987. National Hospital Discharge Survey. 
increases to the considerable rise in the number of physician visits for complaints of oesophagitis, although supportive evidence is lacking.

Data presented show elegantly the improving chances of survival with gastric and large bowel cancer - albeit with a modestly rising frequency of colorectal cancer. ${ }^{12-14}$

The overall impression is of trends in disease frequency that generally parallel those seen in Western Europe. However, the detailed data presented, the critiques of the material, and the commentaries on interpretation make this a particularly valuable set of information. The United Kingdom, and Europe in general, could do with something like it.

Faculty of Medicine and Dentistry,

M J S LANGMAN

The Medical School, Birmingham B15 2TT

1 Everhart JE, ed. Digestive diseases in the United States: epidemiology and impact. National Digestive Diseases Data Working Group. United States Department of Health and Human Services. National Institutes of Health NIH Publication No 94.1447 United States Department of Health and Human Services, 1994.

2 Collins JG. Prevalence of selected chronic conditions United States 1979-81. Vital and Health Statistics Series 10 No 155.
3 Adams PF, Hardy AM. Current estimates from the National Health Interview Survey. Vital and Health Statistics Series 10 No 173.

4 Office of Population Censuses and Surveys (OPCS). Decennial Supplemen Occupational Mortality 1979-80. London: OPCS, 1986.

5 Friedman GD, Sigelaub AB, Seltzer CC. Cigarettes, alcohol, coffee and peptic ulcer. N Engl f Med 1974; 290: 469-73.

6 Sonnenberg A, Sonnenberg GS. Occupational mortality from gastric and duodenal ulcer. Br f Ind Med 1986; 43: 50-5.

7 Walt R, Katschinski B, Logan RFA, Ashley J, Langman MJS. Rising frequency of ulcer perforation in elderly people in the United Kingdom. quency of ulcer perforatio
Lancet 1986; i: $489-93$.

8 Logan RFA, Langman MJS. Gastrointestinal disease - public health aspects. 2nd ed. Vol 3. In: Holland WW, Detels RD, Knox G, eds. Oxford Textbook of Public Health. Oxford: Oxford Medical Publications, 1991

9 Corfield AP, Copper MJ, Williamson RCN. Acute pancreatitis - a lethal disease of increasing incidence. Gut 1985; 26: 724-8.

10 Allum W, Fielding J, Powell J, Langman MJS. Increasing numbers of W A1445.

11 Blot WJ, Devesa SS, Kneller RM, Fraumeni JF Rising incidence of adenocarcinoma of the esophagus and gastric cardia. $\mathcal{F A M} A$ 1991; 265: 1287-9.

12 Sipponnen P, Jarvi O, Kekki M, Sinrala M. Decreased incidences of intestinal and diffuse types of gastric carcinoma in Finland during a 20 year period. Scand $\mathcal{F}$ Gastroenterol 1987; 22: 865-71.

3 Fielding JWL, Powell J, Allum WH, Waterhouse JAH, McConkey CC, eds Cancer of the stomach. Clinical cancer monographs. Vol 3. London: MacMillan, 1989.

14 Slaney G, Powell J, McConkey CC, Waterhouse JAH, Woodman CBJ, eds. Cancer of the large bowel. Clinical cancer monographs. Vol 4. London: MacMillan, 1991. 